Dr. Ludford then opened up the meeting for discussion. Many interesting points were raised, among which was a question by Dr. A. J. Marshall as to whether the Oxford workers had at any time, in their numerous preparations, seen a canalicular structure. Dr. Baker said that Dr. W. S. Morgan (late of Oxford) had seen the canals in fixed preparations of acinous cells of the pancreas; but that he [Dr. Baker] could not say whether or not they existed, though he could say that they should not be called Golgi bodies.

The main issue which emerged from this symposium was whether or not the term 'Golgi apparatus' (or 'Golgi body', etc.) should be used. According to the Oxford workers it denotes homology between objects believed by these workers to be mainly artefacts, the true form of which is represented by lipoidal bodies which may differ chemically from one another. The Oxford work is, however, based mainly on the results of one invertebrate cell (the neurones of $L$. migratoria) and on two kinds of intestinal cells (epithelial and Paneth). Further, their artefact theory probably cannot be accepted in at least four very different kinds of vertebrate cells (neurones, exocrine and endocrine cells of the pancreas, and epididymis cells), where the evidence from so many sources (fixed, ultracentrifuged, frozen-dried, electron microscope studies and vital examination) leaves little doubt that the Golgi network does exist in life. This latter work shows clearly, too, that the network is not represented by lipoidal bodies, and all the Oxford studies emphasizing chemical dissimilarity are studies on the lipoidal bodies. It is clear that such lipoidal bodies may not be homologous. From the classical point of view, Prof. Gatenby has given seven reasons why he accepts homology between the Golgi dictyosomes of invertebrates and the Golgi network (or canals) of vertebrates and retains the general term Golgi apparatus. 'Ihe crux of the matter is whether, as yet, there is sufficient evidence of an incontrovertible nature, on a large enough number of invertebrate and vertebrate cells, to justify a change in nomenclature which will affect some two thousand papers.

A full account of the symposium and the discussion which followed will be published in the Journal of the Royal Microscopical Society.

DENNIS LACY

\section{THE IMMOBILIZATION OF MINERAL NUTRIENTS IN TROPICAL SOILS}

$\mathrm{M}$

ESSRS. W. V. Bartholomew, J. Meyer and H. Laudelout, of the Institut National pour l'Étude Agronomique du Congo Belge (I.N.E.A.C.), have published a paper which should be of considerable interest to all who are concerned with the underlying causes of fertility and infertility of tropical soils (Publ. I.N.E.A.C., Sér. Sci. No. 57, $1-53,1953 ; 30$ f.). They have tackled the problem. of the immobilization of mineral nutrients under forest and grass fallow in the Yangambi region of the Belgian Congo, and they have given some attention to the decomposition of plant debris on the forest floor. Some understanding of these matters is essential to rational agricultural practice, especially in those regions where the inherent soil fertility is not very great, where it may be of a fleeting character, or where it may indeed be almost incredibly low. In the native rain forest a large proportion of the available plant nutrients is immobilized in living organisms - mostly forest trees and vines-but large quantities of plant tissue (mainly leaves and branches) are constantly being deposited on the forest floor, where they decompose and return their nutrient content to the soil. The reabsorption of these nutrients by elements in the flora and fauna is so rapid in the rain forest that, in the case of an acid sandy soil which was studied, the available supply in the soil was found to be continually kept at an exceptionally low level. The authors consider that under a plant cover with high nutrient demands, it is unlikely that many nutrients are lost by fixation or leaching.

When a forest is folled and a crop established, the transition phase is often attended by the temporary liberation of large quantities of mineral nutrients to the soil and by an accelerated loss of nitrogen, particularly if the area is burned over, as is frequently the contemporary practice. In such instances there may be a considerable, even a high, loss of plant nutrients before the crop has grown sufficiently to re-immobilize most of them. In the usual cultivation practices, however, the new crop is typically established concurrently with the disintegration and decomposition of the forest debris ; but even so the utilization of all the nutrients may not keep pace with mineralization, and excessive nutrient losses may result.

Native cropping practices in the Central Congo Basin usually permit the return of forest species within 2-3 years after the forest is felled, and the ensuing fallow or regeneration period may continue for about fifteen years, where there is government supervision; but it may be considerably less. While this kind of soil management has its defects both in terms of soil fertility and labour, it "appears to be a practical solution to the soil management problems where land is in good supply, demand is not great for agricultural products, transportation to market and supply is long and costly, and where local fertilizer resources are either non-existent or not developed".

In both forest and grass fallow the authors point to two factors as being of first importance in enhancing soil fertility, namely, the accumulation of nutrients in organic combinations and the prevention of their loss by plant immobilization, and the improvement of soil structure by rest from eultivation and by biological activity.

The use of grass fallow as an alternative for short rotations has been considered, but its value in native agriculture requires fuller exploration. The maximum usefulness of grasses as fallow crops is probably attained within a few years. It has been observed that after two to four years the rate of root formation reaches a maximum and that decomposition of the grass residues proceeds as rapidly as the new growth is formed; that is, a maximum immobilization of plant nutrients in organic form has been attained. Thereafter, the chief effects of an extension of the fallow period would be to improve the soil texture.

As the immobilization of mineral nutrients may be the most important means of evaluating the useful. ness of fallow systems, an investigation was carried out to obtain some indication of the actual amounts of nutrients immobilized under forest fallow con- 
ditions after different periods of time and to compare the effects of grass and forest fallows. The sites selected for sampling in the more mature forest fallow areas were approximately $10 \times 30$ metres. All the vegetation of suitable and representative sub-plots was collected and weighed green at the site, leaves being separated from branches and trunks from roots. Samples of these materials were duly analysed for their water, mineral and organic contents. Litter samples, subdivided into foliar and stem materials, were similarly analysed. Grass samples were taken from replicated plots of different species representative of fallow areas. It was found that the immobilization of nutrients in the forest fallow is initially rapid: in the first five years more than half the total amount immobilized in eighteen years is accounted for. Leaf growth rapidly approaches a maximum, the later increases in total growth being chiefly due to the accumulation of woody materials, especially in the aerial parts. Roots also approach a maximum at a rather rapid rate. The data at five years show 75 per cent as much growth as at eighteen years. Litter accumulation from leaf and stem residues approaches a maximum some time between eight and twelve years.

In grass fallows, it was noted that a large part of the total harvested material consisted of litter in various stages of decomposition, this being in sharp contrast to either the quantity or proportion of litter in the forest fallow plots. The total root weight in the grass fallows was considerably less than in the forest fallow, though the small and fibrous character of grass roots must here be borne in mind.

The distribution of the nutrients in the different plant parts is important. Thus, leaves comprise only a small proportion of the total weight of plant material except during the early stages; woody tissues, of both stems and roots, account for most of the total weight. In the immobilization of nutrients, however, leaves are considerably more important than woody tissue, particularly in the uptake and release of nitrogen. The woody tissues contain the major proportion of all nutrients, except in very early stages of the fallow, and are particularly important as repositories of the cations and phosphorus.

In the grass plots, it was found that the litter contained a large proportion of the plant nutrients, the roots accounting for only 10-20 per cent. Also, grass is relatively higher in phosphorus and potassium and lower in calcium and magnesium than forest fallow. In the investigators' view, for short fallow systems, the grass fallow compares favourably with the forest fallow, in that it appears to absorb nitrogen and phosphorus at a more rapid rate in the early stages of development. It could not, however, be expected to immobilize the large total quantity of nutrients found in a mature forest fallow.

The rate of nutrient release from fallow forest residues after clearing for cultivation was not specifically studied; but estimates based on the data of decomposition experiments and on a knowledge of mineralization processes of plant materials yield some points of considerable practical importance. Burning of forest fallow or grass fallow releases the immobilized nutrients immediately, a large proportion of the bases (potassium, calcium, magnesium, etc.) and phosphorus being deposited as the oxides on the soil surface; nitrogen, on the other hand, is almost totally lost into the atmosphere, either as free nitrogen or as volatile oxides. After burning, it is, of course, the availability of nutrients that is of special interest and this may present problems of some complexity. Thus, the phosphorus may be partly fixed in relatively unavailable form before the newly planted crops can absorb it; and potassium may be fixed, or lost through drainage. The available nitrogen, on the other hand, because of its release from immobilization in the woody tissues, may be higher immediately after burning than where the vegetation is simply allowed to decay. In general, if the fallow vegetation cover is not burned, its nutrients will tend to be retained in organic combination until they are released by the action of micro-organisms. The major part of the nitrogen, phosphorus and other mineral nutrients is rapidly liberated in mineral form, but, simultaneously, these are taken up again in the synthesis of the cellular materials of the invading micro-organisms. The net difference between mineralization on one hand and this new immobilization on the other gives a measure of the nutrients available for use by crop plants. During vegetable decomposition, potassium and phosphorus are lost more rapidly than nitrogen. In plant residues and in micro-organisms, the ratio of nitrogen to phosphorus approached $7-8: 1$. In soil organic matter Pearson and Simonson found ratios ranging from $7 \cdot 0: 1$ to $15 \cdot 7: 1$ with a mean of about $9 \cdot 3: 1$. The authors record that the litter from the forest fallow plots, and litter gathered from the native forest, had a nitrogen to phosphorus ratio of about $25: 1$. In the residue from the decomposition of the mixed forest leaves the ratio was $32: 1$, and in the decomposed litter from the grass plots it was $12: 1$. They consider that it is unlikely that nitrogen could be rapidly liberated during the initial stages of decomposition of forest or fallow vegetation, as the organisms causing decomposition will initially reabsorb a part of it. Hence, burning the fallow vegetation may actually result in a better nitrogen supply during the early stages of utilizing forest or fallow land than natural decomposition after felling but without burning.

The release of phosphorus from decomposing vegetation is likely to be more rapid than that of nitrogen; and potassium, calcium and magnesium should be rapidly released because of their relatively low utilization in the metabolism of micro-organisms. In the case of potassium this rapid loss was demonstrated experimentally. But calcium and magnesium, though they are liberated and made available, form various insoluble salts, for example, carbonates, sulphates and phosphates. They are not removed by leaching and remain as a part of the decomposed residue. This property makes difficult the measurement of mineralization. The authors conclude that mineralization of nitrogen and phosphorus from grass fallow will, in general, be more rapid than from forest fallow. Potassium from grass fallow will be similar to that from forest fallow, but in each case the rate of release would be related to the total quantity immobilized. Calcium and magnesium were found to be low in the grass samples examined and therefore are not likely to be supplied rapidly from such fallow systems. They also point out that the decay of forest residues may not provide a balanced nutrient supply for some crops and that the relative concentration of available nutrients may undergo important changes during the course of the decom. position; for example, nitrogen may be immobilized to a much greater extent than the other nutrients. The liberation of the elements through biological 
decomposition is a slow process and in 4-6 months forest fallow residues may yield no more than 30 to 50 per cent of the total potassium or calcium and magnesium, and 15-30 per cent of the total phosphorus, while the percentage release of nitrogen may be even smaller.

\section{TOBACCO RESEARCH BOARD OF SOUTHERN RHODESIA}

\section{NEW HEADQUARTERS STATION AT KUTSAGA \\ BY DR. F. A. STINSON}

Director of Tobacco Research, Southern Rhodesia

$\mathrm{T}$ O solve the production problems of the expanding tobacco industry in Southern Rhodesia, the growers and Government jointly established in 1950 the Tobacco Research Board. Interest and confidence of growers in results of research have been considerable, owing to their representation on the Board and to the direct financial contribution they make toward it-more than $£ 2$ for every $£ 1$ provided from general taxation.

The Board's research approach is agronomic in its broad sense, and the investigations on crop rotations serve to illustrate this. Comprehensive rotation experiments were developed owing to the inadequacy of systems of cropping used on farms in all tobaccogrowing areas. Their design permits comparing the effects, on yield and quality of tobacco, of growing many different crops in various sequences with a range of fertilizer practices, management and methods of crop disposal. Study of crop nutrition, soil organic matter and methods of disease, insect and eelworm control is also an integral part of these projects.

Experiments of lattice and factorial designs are used extensively to examine effects of inter-related production factors. Simultaneous examination of the important factors bearing on a specific problem has helped to minimize the dissipation of energy which would otherwise result if, in evaluating methods of controlling a leaf spot disease, for example, such important factors as date of planting, soil fertility and the effects of cropping systems on eelworm incidence were overlooked.

The excessive drainage and excellent aeration that make Rhodesian sandvelds so suitable for flue-cured tobacco pose special problems in humus replenishment and fertility maintenance. The abundance of available nutrients required for rapid growth and economic yields, along with the sensitivity of leaf quality to changes in nutrient balance, give nutritional research-both in the field and in the laboratory-a high priority in the programme. Present fertilizer investigations include examination of rates of use and sources of nitrogen, phosphorus, potassium and magnesium. Methods of fertilizer placement and the efficiency of nitrogen and potassium when applied fractionally, as well as responses to trace elements applied singly and in combinations, are being examined. Disease, insect and eelworm control investigations occupy an important place in the Board's work. Methods of producing tobacco seedlings, as well as cultural and curing practices, receive attention. The varietal improvement work includes testing and comparing the ability of particular varieties to produce high quality and yield, as well as evaluating their resistance to various diseases and types of eelworm damage. Breeding work in progress is designed to introduce resistance or immunity while, at the same time, further improving the leaf qualities of those varieties now in common use for commercial production. By introducing improved varieties, materials and methods as standard treatment in all field experiments as soon as their superiority is indicated by research, such factors are proved on a farm scale before being offered to farmers in the form of recommendations.

The procedure in laying out field experiments has been standardized within the organization. Fields are divided into ranges and permanently benchmarked to accommodate $60-\mathrm{ft}$. rows of tobacco. Plots differ in width only; the number of rows per plot varies from one to eight, depending on the nature of the experiment. A permanent rystem of roadways and surface drainage is provided by placing the $60-\mathrm{ft}$. wide ranges $25 \mathrm{ft}$. apart, each intervening strip consisting of a broad-based terrace and a broad, shallow channel. The direction of ranges to field slope is adjusted so that the fall in the rows of tobacco and in the drainage channels ensures surface drainage without causing erosion. Ant-heaps up to $100 \mathrm{ft}$. in diameter and rock outcrops, common in Rhodesian tobacco-farming districts, complicate the siting of field experiments.

An important stage in the organization's development was marked by the formal opening of the Kutsaga Station on January 21 this year. This Station, which is near Salisbury, is now the headquarters of the Tobacco Research Board. Before Kutsaga was established, the Trelawney Station, opened by the Government in 1934 and leased to the Board in 1950, was the centre of tobacco research, and it will be operated in future as a branch station.

Kutsaga occupies 585 acres alongside the new national airport, ten miles south of the Federal capital. The research building provides spacious chemical and biological laboratories, a library, staff canteen and stores; the addition of two laboratory wings is anticipated. The laboratories are fitted with electricity, gas and hot and cold water. The CapeDutch design of the building blends with its natural surroundings of indigenous trees on a sandy slope typical of those in much of the tobacco-growing region. The slate roof, the teakwood terrazzo floor and the mukwa panels and fittings are in keeping with the importance of the country's largest industry which the Board serves. At the rear of the main building is a 100-ft. greenhouse and headhouse containing a laboratory and storage and potting room. Farm buildings for handling, curing and grading leaf from experimental plots were ready for the 1953-54 crop. Modern residences have been erected on the Station for key staff members, and substantial brick homes, with modern plumbing and sanitation, are being provided for all African employees and their families.

Staff are encouraged to obtain postgraduate experience outside Rhodesia, the Board's paid studyleave scheme being designed to facilitate this advanced training. There are also bursaries to assist aboveaverage Rhodesian students to qualify at leading universities preparatory to employment by the Board. At present the Board has a professional staff of fifteen, including a biometrician.

The Board is aware of the importance of keeping the sponsors, especially tobacco growers, fully informed on the progress made. The frequent publication of reports of progress, bulletins and interim: 